\title{
Advanced degradation of brominated epoxy resin and simultaneous transformation of glass fiber from waste printed circuit boards by improved supercritical water oxidation processes
}

\author{
Kang Liu, Zhiyuan Zhang, Fu-Shen Zhang* \\ Department of Solid Waste Treatment and Recycling, Research Center for Eco-Environmental Sciences, Chinese Academy of Sciences, 18 Shuangqing Road, Beijing 100085, China \\ University of Chinese Academy of Sciences, Beijing 100049, China
}

\section{A R T I C L E I N F O}

\section{Article history:}

Received 19 February 2016

Revised 11 May 2016

Accepted 21 May 2016

Available online 7 June 2016

\section{Keywords:}

Waste PCBs

Advanced degradation

Supercritical water

Mechanism

Anorthite

\begin{abstract}
A B S T R A C T
This work investigated various supercritical water oxidation (SCWO) systems, i.e. SCWO1 (only water), SCWO2 (water $+\mathrm{H}_{2} \mathrm{O}_{2}$ ) and SCWO3 (water $+\mathrm{H}_{2} \mathrm{O}_{2} / \mathrm{NaOH}$ ), for waste printed circuit boards (PCBs) detoxification and recycling. Response surface methodology (RSM) was applied to optimize the operating conditions of the optimal SCWO3 systems. The optimal reaction conditions for debromination were found to be the $\mathrm{NaOH}$ of $0.21 \mathrm{~g}$, the $\mathrm{H}_{2} \mathrm{O}_{2}$ volume of $9.04 \mathrm{~mL}$, the time of $39.7 \mathrm{~min}$, maximum debromination efficiency of $95.14 \%$. Variance analysis indicated that the factors influencing debromination efficiency was in the sequence of $\mathrm{NaOH}>\mathrm{H}_{2} \mathrm{O}_{2}>$ time. Mechanism studies indicated that the dissociated ions from $\mathrm{NaOH}$ in supercritical water promoted the debromination of brominated epoxy resins (BERs) through an elimination reaction and nucleophilic substitution. $\mathrm{HO}_{2}$, produced by $\mathrm{H}_{2} \mathrm{O}_{2}$ could induce the oxidation of phenol ring to open (intermediates of BERs), which were thoroughly degraded to form hydrocarbons, $\mathrm{CO}_{2}$, $\mathrm{H}_{2} \mathrm{O}$ and $\mathrm{NaBr}$. In addition, the alkali-silica reaction between $\mathrm{OH}^{-}$and $\mathrm{SiO}_{2}$ induced the phase transformation of glass fibers, which were simultaneously converted into anorthite and albite. Waste PCBs in $\mathrm{H}_{2} \mathrm{O}_{2} / \mathrm{NaOH}$ improved SCWO system were fully degraded into useful products and simultaneously transformed into functional materials. These findings are helpful for efficient recycling of waste PCBs.
\end{abstract}

(c) 2016 Elsevier Ltd. All rights reserved.

\section{Introduction}

Supercritical water oxidation (SCWO) has recently grown as a green process for treating toxic organic compounds (Qian et al., 2016; C. Wang et al., 2011; S. Wang et al., 2011). Supercritical water is relatively non-polar because of diminished hydrogen bonding allowing organic species, oxygen, and water to form a single homogeneous phase, which results in rapid oxidation due to the elimination of mass transport limitations at the interface. The unique properties of supercritical water, such as its miscibility with oxygen in all proportions, negligible surface tension, high diffusivity, low viscosity, and low solubility of inorganic salts, make it an ideal for treatment of toxic compounds and most toxic organic compounds are rapidly oxidized in supercritical water (Bröll et al., 1999; Savage, 1999).

Waste printed circuit boards (PCBs), including organic polymers, glass fibers, and various metals, are difficult to dispose of due to its complicated composition (Fogarasi et al., 2015; Hadi et al., 2015; Zhang et al., 2012). Besides, there are large amounts

\footnotetext{
* Corresponding author.

E-mail address: fszhang@rcees.ac.cn (F.-S. Zhang).
}

of bromine flame retardants and heavy metals in waste PCBs. If such kinds of electronic wastes are disposed in improper ways such as discard or landfill in a random way, the heavy metals and organic pollutants may infiltrate into groundwater and soil. Through such natural processes of migration, conversion, food chain cycle and biological concentration, it will consequently do harm to ecological environment and further pose risk to human health and life safety (Duan et al., 2011; Huang et al., 2009). At present, active researches related to recycle of waste PCBs have been focused on pyrometallurgy and hydrometallurgy (Akcil et al., 2015; Quan et al., 2010; Wang and Xu, 2014; Yang et al., 2011). However, these methods generally involve a number of drawbacks from an environmental point of view, e.g. low treatment efficiency, high treatment cost, secondary pollution and poisonous gases (Huang et al., 2009; Li et al., 2012). Hence, considering alternatives for recycling these materials in an environmental benign process is attracting the attention of many researchers in different fields.

SCWO has ever been used as an environmentally friendly method for treating hazardous organic polymers in electronic waste, which are broken down into small molecules (Wang et al., 2015; Xiu et al., 2013, 2015). Actually, most recent studies in this field have focused on this method of degradation (Xing and 
Zhang, 2013; Yin et al., 2011). Compared with the traditional pyrometallurgy and hydrometallurgy, the SCWO method of treating waste PCBs has many advantages, including no production of volatile organic compounds, no emission of poisonous and hazardous gas, high metal recovery rate and cleaner production process. Table 1 summarizes the previous research about using SCWO techniques to dispose waste PCBs. From Table 1, it can seen that high-molecular polymers in the waste PCBs could effectively degrade into low molecular organic compounds in SCWO system, and valuable metals could be also recovered simultaneously. Despite its advantages, the SCWO method of treating waste PCBs presents certain problems. For instance, brominated epoxy resins (BERs) are degraded into phenols and $\mathrm{HBr}$ in supercritical water. Discharge of phenols should be limited as they are harmful compounds that pollute the air and water (Ding et al., 1995). Thus, it is urgent to develop an environmentally friendly SCWO system that can convert the polymers and glass fibers directly or indirectly originating from oil products to usable chemical products or materials. This new SCWO system not only improves the recycling rate of waste PCBs, but also helps to eliminate ecological risks that result from landfill, incineration or pyrolysis.

The aim of the present study was to develop an improved SCWO system for waste PCB disposal. The improved SCWO system $\left(\mathrm{H}_{2} \mathrm{O}_{2}\right.$ or $\mathrm{H}_{2} \mathrm{O}_{2} / \mathrm{NaOH}$ as additive) could successfully convert waste PCBs into chemical products and functional materials with high added value. Meanwhile, harmful impact caused by waste PCBs to the environment could be completely eliminated. The effects of various SCWO systems on the debromination of BERs were evaluated. The degradation and transformation mechanisms of waste PCB components in various SCWO systems were also discussed in detail.

\section{Experiment}

\subsection{Materials}

Waste PCBs were supplied by XIAMEN OASIS Sources Co., Ltd. The composition of the waste PCBs is given in Table 2. All other chemicals were analytical grade and were purchased from Chemical Reagent Company of Beijing.

\subsection{Treatment process}

Waste PCBs were shredded and crushed by a universal pulverizer before SCWO treatment. The powder was passed through an 80 -mesh filter and dried in an oven at $100{ }^{\circ} \mathrm{C}$ for $1 \mathrm{~h}$. SCWO experiments were conducted in a $100 \mathrm{~mL}$ high-pressure reactor made of 316 alloys. Three SCWO systems, i.e. SCWO1 (only water), SCWO2
Table 2

Composition of the waste PCBs sample (wt\%).

\begin{tabular}{ccccc}
\hline $\begin{array}{c}\text { Component } \\
\text { Elemental }\end{array}$ & $\begin{array}{c}\text { Organics } \\
\mathrm{CH}_{\mathrm{n}} \mathrm{O}_{\mathrm{m}} \mathrm{Br}\end{array}$ & $\begin{array}{c}\text { Glass fiber } \\
\mathrm{CaO} \text { and } \mathrm{SiO}_{2}\end{array}$ & \multicolumn{2}{c}{ Metals } \\
\cline { 3 - 5 } & 43.12 & 45.22 & $\mathrm{Cu}$ & $\mathrm{Al}$ \\
\hline Content (\%) & 4.80 & 3.86 \\
\hline
\end{tabular}

(water $+\mathrm{H}_{2} \mathrm{O}_{2}$ ) and SCWO3 (water $+\mathrm{H}_{2} \mathrm{O}_{2} / \mathrm{NaOH}$ ), were investigated for the treatment of waste PCBs. The reaction conditions for each experiment are described in Table 3. The schematic diagram and physical map of supercritical hydrothermal reactor are described in Figs. S1 and S2, respectively.

SCWO experiment process: $2.5 \mathrm{~g}$ waste $\mathrm{PCBs}$ powder, $40 \mathrm{~mL}$ water and a certain proportion of additive $\left(\mathrm{H}_{2} \mathrm{O}_{2}\right.$ or $\left.\mathrm{H}_{2} \mathrm{O}_{2} / \mathrm{NaOH}\right)$ were introduced into the supercritical hydrothermal reactor. Hydrogen peroxide $\left(\mathrm{H}_{2} \mathrm{O}_{2}, 30 \mathrm{wt} \%\right)$ that don't decompose at the room temperature released oxygen dissolved into supercritical water $\left(\mathrm{H}_{2} \mathrm{O}_{2}=\mathrm{H}_{2} \mathrm{O}+1 / 2 \mathrm{O}_{2}\right)$. The reactor was heated to a selected temperature. The pressure inside the reactor was monitored by a pressure gauge attached to the reactor. Once the reactor had reached the selected temperature, it was held at this temperature for selected residence time. After the SCWO reaction, the reactor was cooled naturally to the room temperature. The SCWO residue and the supernatant were separated by vacuum filtration. The SCWO residue was washed by deionized water.

\subsection{Analysis methods}

Oxygen combustion bomb-ion chromatography (IC, Dionex ICS2000, USA) was used to determine the bromine content of the solid residue. Debromination efficiency was calculated from the bromine content before and after SCWO. The organic products after SCWO treatment were analyzed with gas chromatography mass spectrometry (GC/MS, Agilent 7890A/5975C, USA).

The crystalline phases of the waste PCBs and the solid samples were characterized using X-ray diffraction (XRD, Bruker D8 X-ray powder diffractometer) at $50 \mathrm{kV}$ and $100 \mathrm{~mA}$ using $\mathrm{Cu} \mathrm{K} \alpha$ radiation ( $\mathrm{k}=1.5418 \AA$ ). The morphological properties and element content of the SCWO residue were examined using scanning electron microscopy and energy disperse X-ray analysis (SEM-EDX, Hitachi S-3000 N, Japan).

\subsection{Statistical analyses}

The response surface methodology (RSM) was used to analyze the interaction of several independent factors by the

Table 1

Summary of waste PCBs treatment using SCWO method.

\begin{tabular}{|c|c|c|c|c|c|c|c|}
\hline Sample & Additive & $\mathrm{T}\left({ }^{\circ} \mathrm{C}\right)$ & $\begin{array}{l}\text { Time } \\
(\min )\end{array}$ & $\begin{array}{l}\text { Organic } \\
\text { products }\end{array}$ & Metal products & $\begin{array}{l}\text { Non metallic } \\
\text { products }\end{array}$ & Reference \\
\hline Waste memory modules & None & $350-550$ & $120-360$ & Phenol, $\mathrm{HBr}$ & $\mathrm{Cu}, \mathrm{Au}$ & $\mathrm{SiO}_{2}$ & Li and Xu (2015) \\
\hline Waste PCBs & None & $200-400$ & $30-120$ & Phenol, $\mathrm{HBr}$ & $\mathrm{Cu}$ & $\mathrm{SiO}_{2}$ & Xing and Zhang (2013) \\
\hline Waste PCBs & None & $280-400$ & $0-90$ & Not detected & $\mathrm{Cu}, \mathrm{Au}$ & $\mathrm{SiO}_{2}$ & $\begin{array}{l}\text { Matsumoto and Oshima } \\
\text { (2014) }\end{array}$ \\
\hline Waste PCBs & $\mathrm{NaOH}$ & $320-520$ & 10 & Phenol, $\mathrm{NaBr}$ & $\begin{array}{c}\mathrm{Cu}_{2} \mathrm{O}, \mathrm{Cu}(\mathrm{OH})_{2} \\
\mathrm{CuO}\end{array}$ & Not detected & Chien et al. (2000) \\
\hline Waste PCBs & $\begin{array}{l}\mathrm{NaCl} / \mathrm{HAc} / \\
\mathrm{NaOH}\end{array}$ & $240-400$ & $0-60$ & $\begin{array}{l}\text { Phenol, } \mathrm{HBr} / \\
\mathrm{NaBr}\end{array}$ & Not detected & Not detected & Yin et al. (2011) \\
\hline Waste PCBs & $\begin{array}{l}\text { Polyvinyl } \\
\text { chloride }\end{array}$ & $150-400$ & $0-180$ & Not detected & $\mathrm{SnO}_{2}, \mathrm{CuCl}_{2}$ & Not detected & Xiu et al. (2014) \\
\hline Computer housing plastic & $\begin{array}{l}\mathrm{NaOH} / \mathrm{KOH} / \\
\mathrm{Ca}(\mathrm{OH})_{2}\end{array}$ & $300-420$ & $30-120$ & Phenol, $\mathrm{NaBr}$ & None & None & Wang and Zhang (2012) \\
\hline $\begin{array}{c}\text { Brominated flame-retarded } \\
\text { plastics }\end{array}$ & $\begin{array}{l}\mathrm{NaOH} / \mathrm{KOH} / \\
\mathrm{Ca}(\mathrm{OH})_{2}\end{array}$ & 450 & $0-30$ & Phenol, $\mathrm{NaBr}$ & $\mathrm{Sb}_{2} \mathrm{O}_{3}$ & None & $\begin{array}{l}\text { Onwudili and Williams } \\
\qquad(2009)\end{array}$ \\
\hline
\end{tabular}


Table 3

SCWO experimental conditions.

\begin{tabular}{cccccc}
\hline System & No. & Temperature $\left({ }^{\circ} \mathrm{C}\right)$ & $\mathrm{NaOH}(\mathrm{g})$ & $\mathrm{H}_{2} \mathrm{O}_{2}(\mathrm{~mL})$ & Pressure $(\mathrm{MPa})$ \\
\hline SCWO1 & 1 & 375 & 0 & 0 & 23 \\
& 2 & 400 & 0 & 0 & 28 \\
& 3 & 425 & 0 & 0 & 36 \\
SCWO2 & 1 & 375 & 0 & 20 & 23 \\
& 2 & 400 & 0 & 20 & 28 \\
& 3 & 425 & 0 & 20 & 36 \\
SCWO3 & 1 & 375 & 0.25 & 20 & 23 \\
& 2 & 400 & 0.25 & 20 & 28 \\
& 3 & 425 & 0.25 & 20 & 36 \\
\hline
\end{tabular}

Design-Expert software (version 8.0.5, Stat-Ease, Inc., Minneapolis, $\mathrm{MN}$ ). Experiments were conducted in a standard RSM design called Box-Behnken Design (BBD) for the optimization of debromination efficiency. The $\mathrm{NaOH}$ amount, $\mathrm{H}_{2} \mathrm{O}_{2}$ volume and time were selected as factors on the response debromination efficiency with the coded values at three levels $(-1,0$ and +1$)$. Firstly, single factor experiments were conducted to define the range of operation conditions for respective factors. The results of single factor experiments are shown in Fig. S3. Fig. S3 showed the maximum value of factor A, $B$ and $C$ were $0.15,12$ and 30 , respectively. Therefore, central values were designed into $A=0.15, B=12$ and $C=30$. Before processing the experiment data, it was necessary to code different experiment factors into code values $(-1,0$ and +1$)$ which could be inputted into the Design-Expert software in advance. The ranges and the levels of variables are given in Table 4 .

\section{Results and discussion}

\subsection{Debromination efficiencies of SCWO systems}

The debromination efficiencies of the SCWO systems are shown in Fig. 1. The results in Fig. 1 show that SCWO1 systems were able to debrominate BERs in the waste PCBs. Only a small amount of bromine was detected in the SCWO1 residues, suggesting that oxidation of supercritical water is effective to promote the decomposition of BERs. However, debromination efficiency decreased significantly upon addition of $\mathrm{H}_{2} \mathrm{O}_{2}$ in the SCWO2 systems, suggesting that $\mathrm{H}_{2} \mathrm{O}_{2}$ inhibits the release of bromine from BERs. In the SCWO3 systems, debromination efficiency increased obviously with increasing temperature, and the debromination efficiency of the SCWO3 systems were superior. In the SCWO3 systems, the bromine from the BERs was first released as $\mathrm{HBr}$ and then neutralize by $\mathrm{NaOH}$ to form $\mathrm{NaBr}$, which can reduce the equipment corrosion during the treatment process (Chien et al., 2000). The $\mathrm{pH}$ value of SCWO reaction solution is shown in Fig. S4. Therefore, bromine content in SCWO3 residues can be easily reduced after SCWO3 treatment. These results demonstrate that the addition of $\mathrm{NaOH}$ is important in facilitating debromination and high temperature is beneficial for the BERs debromination.

\subsection{GC-MS analysis of oil products}

The oil-phase products that were produced under the condition of $425^{\circ} \mathrm{C}$ in Table 3 were identified by GC-MS. Fig. 2 shows that

Table 4

Factors and levels of RSM.

\begin{tabular}{cccc}
\hline Independent variables & \multicolumn{3}{c}{ Levels } \\
\cline { 2 - 4 } & -1 & 0 & 1 \\
\hline $\mathrm{A}: \mathrm{NaOH}(\mathrm{g})$ & 0.05 & 0.15 & 0.25 \\
$\mathrm{~B}: \mathrm{H}_{2} \mathrm{O}_{2}(\mathrm{~mL})$ & 4 & 12 & 20 \\
$\mathrm{C}: \mathrm{Time}(\mathrm{min})$ & 0 & 30 & 60 \\
\hline
\end{tabular}

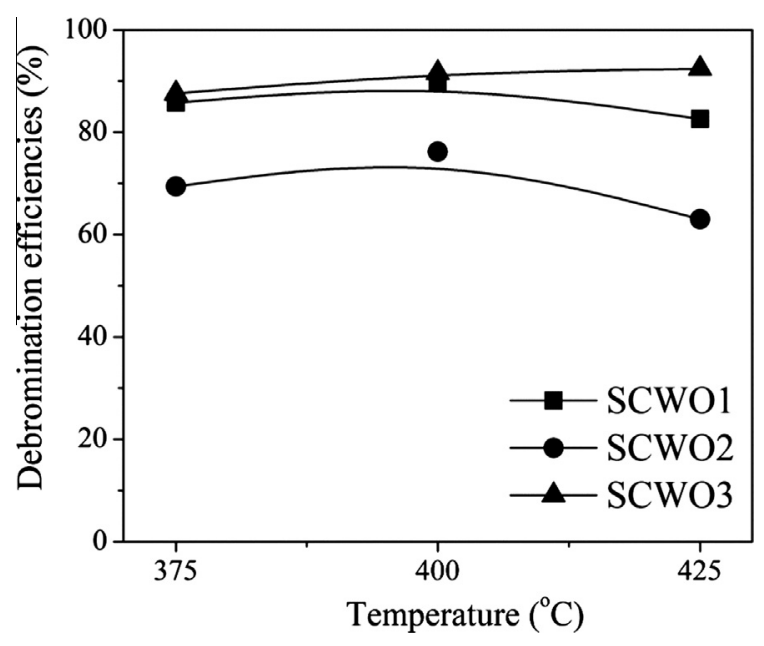

Fig. 1. Debromination efficiencies of various SCWO systems.

the oil-phase products of the SCWO1 systems were mainly phenols. This result was consistent with previous studies ( $\mathrm{Li}$ and $\mathrm{Xu}$, 2015; Xing and Zhang, 2013; Yin et al., 2011). Moreover, the sole addition of $\mathrm{NaOH}$ could increase the debromination efficiency in the SCWO systems, but the degradation products of BERs are still phenol and $\mathrm{HBr}$ (Table 1 ). In contrast, the oil-phase products after treatment by SCWO2 systems and SCWO3 systems were mainly long-chain hydrocarbons. These results indicate that the addition of $\mathrm{H}_{2} \mathrm{O}_{2}$ results in oxidative ring opening of phenols resulting in the formation of hydrocarbons. It is also possible that the addition of $\mathrm{NaOH}$ could reduce the production of oil-phase products. The SCWO3 system was therefore deemed the most efficient system for the removal of bromine and the deep degradation of BERs from waste PCBs.

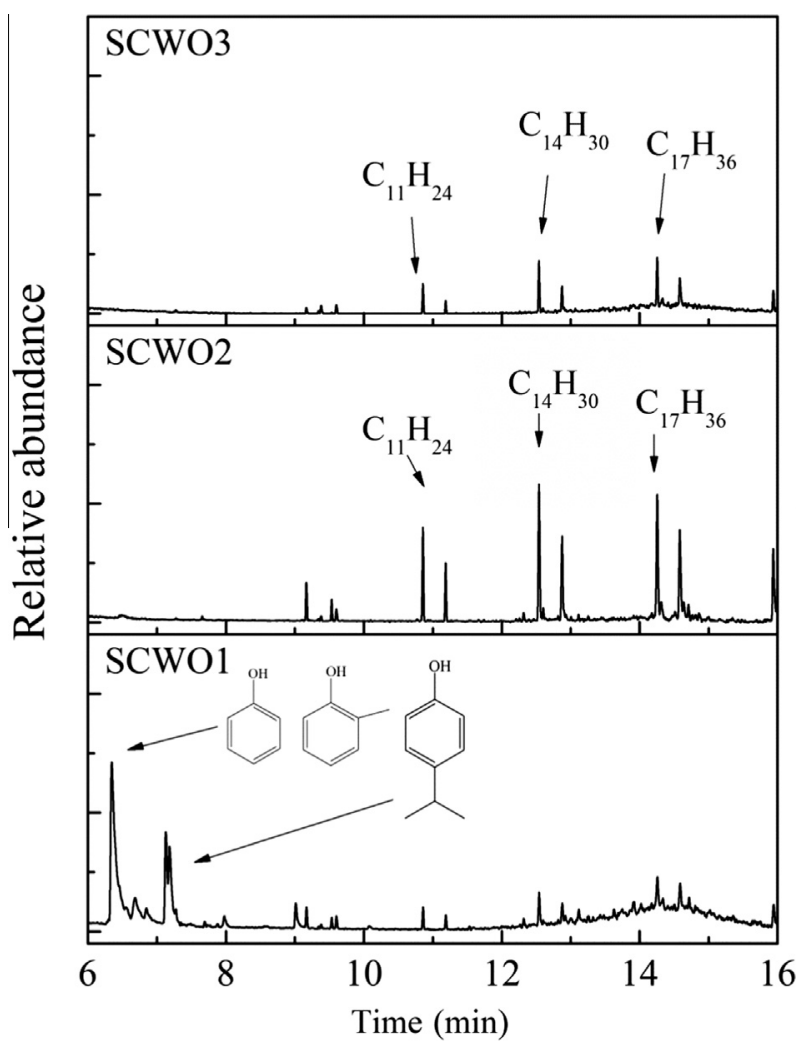

Fig. 2. GC-MS analysis of oil products. 
Table 5

Factors and the experimental responses.

\begin{tabular}{ccccc}
\hline Runs & $\mathrm{A}(\mathrm{NaOH} / \mathrm{g})$ & $\mathrm{B}\left(\mathrm{H}_{2} \mathrm{O}_{2} / \mathrm{mL}\right)$ & $\mathrm{C}(\mathrm{Time} / \mathrm{min})$ & $\mathrm{Y}_{\mathrm{D}}(\%)$ \\
\hline 1 & 0.05 & 4 & 30 & 85.17 \\
2 & 0.05 & 12 & 0 & 87.95 \\
3 & 0.05 & 20 & 30 & 88.80 \\
4 & 0.05 & 12 & 60 & 89.48 \\
5 & 0.15 & 20 & 60 & 89.11 \\
6 & 0.15 & 4 & 60 & 89.0 \\
7 & 0.15 & 20 & 0 & 89.26 \\
8 & 0.15 & 4 & 0 & 88.0 \\
9 & 0.25 & 12 & 0 & 91.69 \\
10 & 0.25 & 20 & 30 & 92.58 \\
11 & 0.25 & 4 & 30 & 88.51 \\
12 & 0.25 & 12 & 60 & 95.09 \\
13 & 0.15 & 12 & 30 & 94.18 \\
14 & 0.15 & 12 & 30 & 94.52 \\
15 & 0.15 & 12 & 30 & 93.97 \\
16 & 0.15 & 12 & 30 & 94.40 \\
17 & 0.15 & 12 & 30 & 94.19 \\
\hline
\end{tabular}

\subsection{Optimization of SCWO3 system parameters}

To obtain the highest debromination efficiency of SCWO3 system, optimum design was developed by applying BBD under RSM. Factors and responses values of BBD are shown in Table 5. The results showed that the debromination efficiency of SCWO3 system varied obviously at different reaction condition. The optimum conditions for the SCWO3 system were determined by means of BBD under RSM. The analysis results were outputted by DesignExpert software 8.0. The response was fitted using the empirical second-order polynomial model. The analyses of variance (ANOVA) are shown in Table 6. As can be seen, the model F-value of 13.86 implies the model is significant. There is only a $0.11 \%$ chance that a "Model F-value" this large could occur due to noise. Values of "prob > F" less than 0.0500 indicate model terms are significant. The interaction between each factor is no significant. In this case, $A, B, A^{2}, B^{2}, C^{2}$ are significant model terms. Furthermore, the results show that the order of factors influenced debromination efficiency is: $\mathrm{NaOH}>\mathrm{H}_{2} \mathrm{O}_{2}>$ time.

The three-dimensional (3D) response surface plots of debromination efficiency under the interaction of different factors were given for better understanding of three variables, which are shown in Fig. 3. As seen in Fig. 3, the debromination efficiency had a growing trend as the $\mathrm{NaOH}$ amount rose. This can be explained that increasing amount of $\mathrm{NaOH}$ can enhance the efficiency of debromination. Besides, the debromination efficiency rose at first and gone down later with the rose of $\mathrm{H}_{2} \mathrm{O}_{2}$ volume. In addition, the debromination efficiency increased with the increase of time. This showed that the extended reaction time was conducive for bromine removal.

Table 6

Results of variance analysis.

\begin{tabular}{cccccc}
\hline Source & Sum of squares & df & Mean square & F-value & Prob $>$ F \\
\hline Model & 141.09 & 9 & 15.68 & 13.87 & 0.0011 \\
$\mathrm{~A}-\mathrm{NaOH}$ & 33.96 & 1 & 33.96 & 30.04 & 0.0009 \\
$\mathrm{~B}^{-} \mathrm{H}_{2} \mathrm{O}_{2}$ & 10.29 & 1 & 10.30 & 9.10 & 0.0195 \\
$\mathrm{C}-\mathrm{Time}$ & 4.17 & 1 & 4.17 & 3.69 & 0.0962 \\
$\mathrm{AB}$ & 0.0450 & 1 & 0.050 & 0.044 & 0.8401 \\
$\mathrm{AC}$ & 0.88 & 1 & 0.88 & 0.79 & 0.4069 \\
$\mathrm{BC}$ & 0.32 & 1 & 0.32 & 0.29 & 0.6086 \\
$\mathrm{~A}^{2}$ & 11.34 & 1 & 11.34 & 10.03 & 0.0158 \\
$\mathrm{~B}^{2}$ & 62.33 & 1 & 62.33 & 55.14 & 0.0001 \\
$\mathrm{C}^{2}$ & 10.25 & 1 & 10.25 & 9.07 & 0.0196 \\
Lack of fit & 7.73 & 3 & 2.58 & 55.93 & \\
Residual & 7.91 & 7 & 1.13 & & \\
Pure Error & 0.18 & 4 & 0.046 & & \\
Cor Total & 149.0 & 16 & & & \\
\hline
\end{tabular}
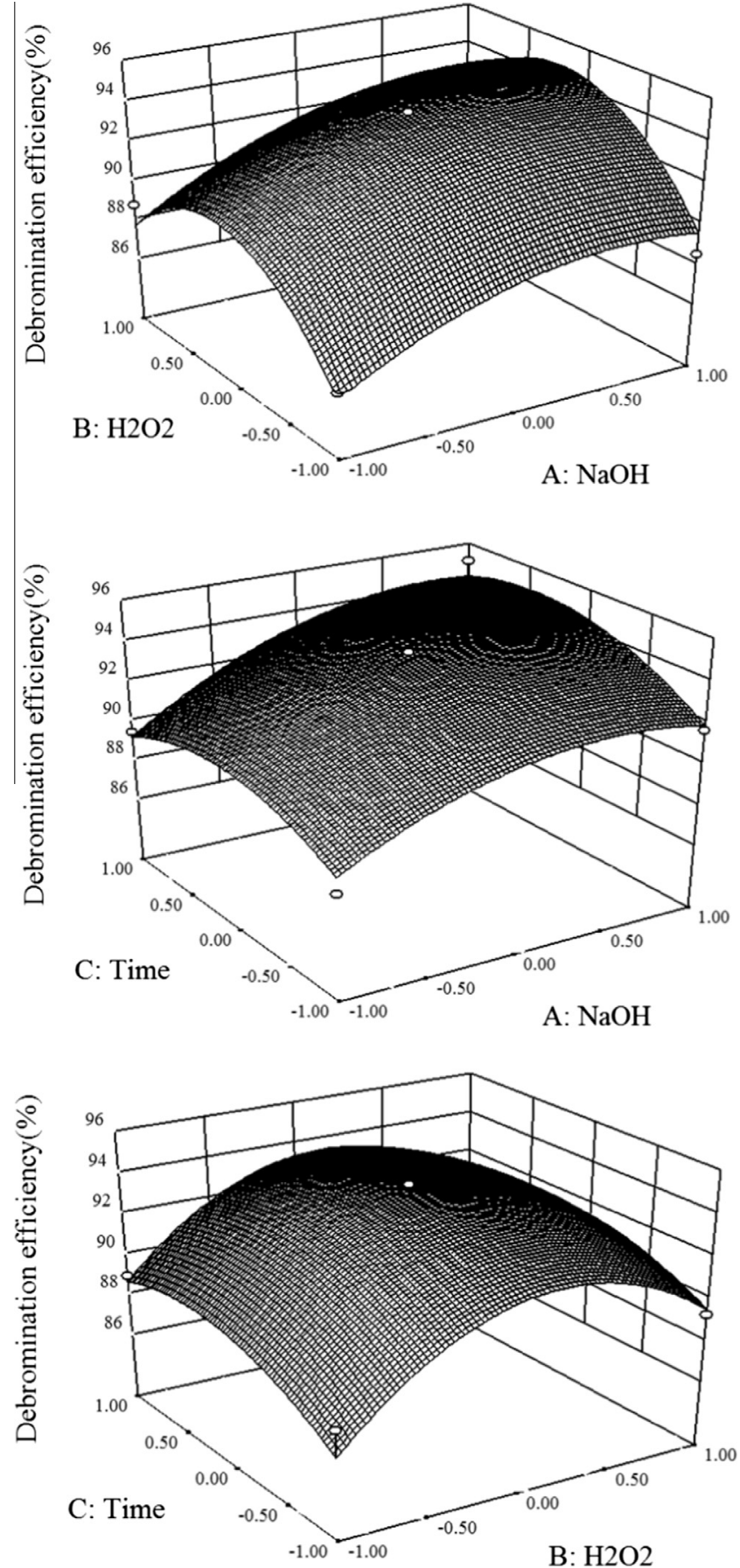

Fig. 3. Response surface 3D plots of debromination efficiency under the interaction of different factors.

The regression analysis was implemented using all the independent variables and their interactions. The coefficients for the modified mode were calculated by Design-Expert software 8.0. The empirical relationship between the debromination efficiency $\left(Y_{D}\right)$ and the three variables can be written as follows:

$$
\begin{aligned}
Y_{D}= & 94.25+2.06 A+1.13 B+0.72 C+0.11 A B+0.47 A C-0.28 B C \\
& -1.64 A^{2}-3.85 B^{2}-1.56 C^{2}
\end{aligned}
$$

By investigating the starting points in the response surface changes, the best solution was found to be the $\mathrm{NaOH}$ of $0.21 \mathrm{~g}$, the $\mathrm{H}_{2} \mathrm{O}_{2}$ volume of $9.04 \mathrm{~mL}$, the time of $39.7 \mathrm{~min}$, maximum 
debromination efficiency of $95.14 \%$. According to the above results, $0.21 \mathrm{~g}, 9.0 \mathrm{~mL}, 40 \mathrm{~min}$ were chosen as the optimal system parameters for debromination. The verification test was performed as the optimal parameters. The results indicate that the efficiency of debromination was $94.61 \%$, which was similar to the predictions. Therefore, the optimal stoichiometric ratio of the SCWO method of treating BERs was $\mathrm{NaOH} 0.19 \mathrm{~g} / \mathrm{g}, \mathrm{H}_{2} \mathrm{O}_{2} 8.35 \mathrm{~mL} / \mathrm{g}$ and the solid-liquid ratio of $26.95 \mathrm{~g} / \mathrm{L}\left(\mathrm{m}_{\text {waste }}\right.$ PCBs $=2.5 \mathrm{~g} ; \mathrm{m}_{\text {BERs }}=1.078 \mathrm{~g}$ for each test).

\subsection{BERs degradation mechanism}

Based on the identified GC-MS products, the probable decomposition pathways of BERs in SCWO3 systems were investigated (Fig. 4). Generally, the degradation of BERs in supercritical water follows a free radical mechanism, where polymers are broken down into small molecules through chain initiation, growth, transmission and termination. When the reaction system provides energy greater than the dissociation energy of chemical bonds in the epoxy resins, those bonds break forming free radicals. These free radicals trigger a chain reaction breaking more bonds, forming new substances and free radicals, which eventually react to form a stable substance, thus terminating the reaction (Hunter and Savage, 2004; Luda et al., 2002).

Under supercritical conditions, high temperatures break down the hydrogen-bonding network between water molecules, which weakens the dielectric shielding effect of the water molecules (Savage, 1999). The solvent water then undergoes homolytic cleavage to form very active $\mathrm{HO}^{\cdot}\left(\mathrm{H}_{2} \mathrm{O} \leftrightarrow \mathrm{H}^{+}+\mathrm{HO}^{\cdot}\right)$, which can attack the weak $\mathrm{CH}_{2}-\mathrm{O}$-benzene ring on the BERs, breaking down the polymers into small molecules. The weak bonds in the small molecules induce further free radical reactions ultimately resulting in bromophenols (1) (2) (3)) (Li and Xu, 2015).

Any $\mathrm{Na}^{+}$which dissociates from $\mathrm{NaOH}$ in SCWO3 system is positively-charged and can react with $\mathrm{Br}$ in bromophenols leading to the formation of $\mathrm{NaBr}$, while $\mathrm{OH}^{-}$mainly undergoes nucleophilic substitution with $\mathrm{Br}$-containing organic substances thereby eliminating $\mathrm{Br}$ (Lin and Wang, 1999). $\mathrm{OH}^{-}$also accelerates the ring opening of benzene rings and further debromination (Chien et al., 2000; Sun et al., 2007). Therefore, both $\mathrm{Na}^{+}$and $\mathrm{OH}^{-}$ions, through different paths, accelerate debromination and promote the removal of $\mathrm{Br}$ from the benzene rings (4)). Thus, the presence of

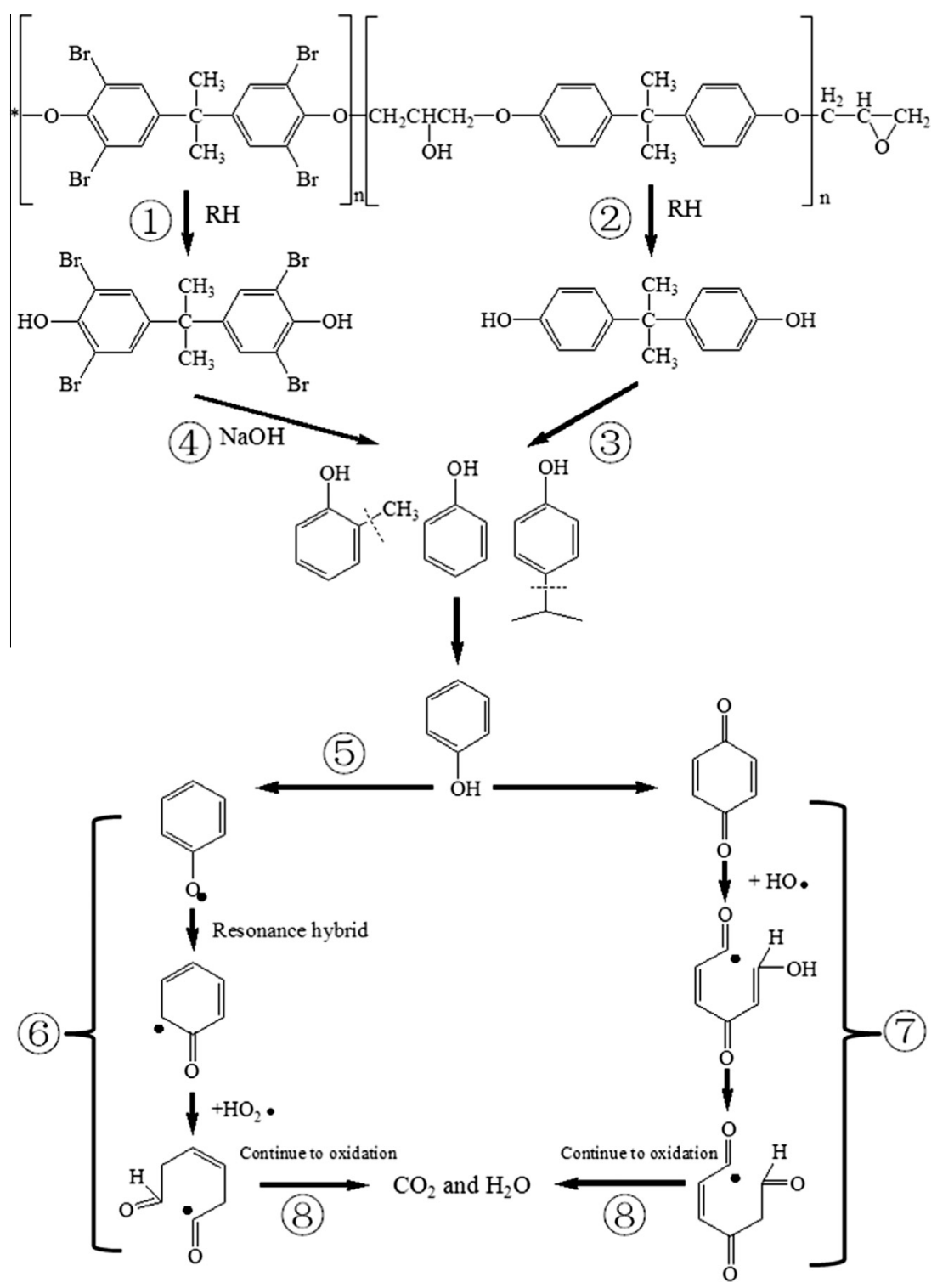

Fig. 4. Degradation mechanism of BERs in SCWO3 system. 
$\mathrm{NaOH}$ in the SCWO3 system accelerates the removal of Br, leading to the highest debromination efficiency.

Hydroxyl in phenol is an electron-withdrawing group, where the electrons from the benzene ring are donated through the inductive effect to the hydroxyl group, facilitating its removal. Thus, transitional product phenol may form benzene oxygen free radical under SCWO conditions (5)) (Gopalan and Savage, 1994). In the ring-opening reaction of phenol, the highly oxidative free radical $\mathrm{HO}_{2}^{-}\left(\mathrm{H}_{2} \mathrm{O}_{2} \rightarrow \mathrm{H}_{2} \mathrm{O}+\mathrm{O}_{2}, \mathrm{H}^{+}+\mathrm{O}_{2} \rightarrow \mathrm{HO}_{2}^{\prime}\right)$ is added to the benzene oxygen free radicals, leading to the transfer of $\pi$ electrons and the destabilization and breakdown of benzene rings. There are two main paths for this reaction. (I) $\mathrm{HO}_{2}$ reacts with the free radical of cyclohexadienone, which is a resonance structure of the benzene oxygen free radical. The steps of this reaction are the rupture of the $\mathrm{O}-\mathrm{O}$ bond, removal of the $\mathrm{HO}_{2}$ radical, migration of free radicals, and opening of the benzene ring (6)). The resulting acyl-group free radicals undergo further fragmentation reactions, decarbonylation and aldehyde removal, resulting in ketone and organic acids, which are ultimately oxidized to $\mathrm{CO}_{2}$ and $\mathrm{H}_{2} \mathrm{O}$ (8)). (II) The oxidation of the phenol group results in $p$-benzoquinone, which contains an unsaturated $\mathrm{C}=\mathrm{C}$ bond that can undergo an additive reaction. HO $\left(\mathrm{H}_{2} \mathrm{O}_{2} \rightarrow 2 \mathrm{HO} \cdot\right)$ can easily abstract protons from most organic reactants $\left(\mathrm{RH}+\mathrm{HO}^{*} \rightarrow \mathrm{R}^{*}+\mathrm{H}_{2} \mathrm{O}\right)$ and can also undergo an additive reaction with the unsaturated $\mathrm{C}=\mathrm{C}$ bond in $p$-benzoquinone. The migration of free radicals leads to the breakdown of the molecule and subsequent ring opening. After enol rearrangement (7)), the resulting ketones can undergo further free radical fragmentation forming organic acids, which are further oxidized to form $\mathrm{CO}_{2}$ and $\mathrm{H}_{2} \mathrm{O}$ (8) (Dong et al., 2015; Guan et al., 2011; Li et al., 2005).

In general, the degradation of BERs in the SCWO3 system results from the oxidation reaction between $\mathrm{HO}^{-}$and $\mathrm{HO}_{2}$ and the $\mathrm{NaOH}$ cation-anion. The degradation process is divided into three major steps: (1) free radical attacks the BERs polymers to form monomers; (2) The intermediates, including bromophenol, are debrominated by $\mathrm{HO}^{\circ}$ and $\mathrm{NaOH}$, and the free radicals released by $\mathrm{H}_{2} \mathrm{O}_{2}$ attack the oxidized ring opened products to form small-molecule organic acids and ketone; (3) The ketone and organic acids are finally oxidized to form $\mathrm{CO}_{2}$ and $\mathrm{H}_{2} \mathrm{O}$. As confirmed by analysis of the degraded products, steps (1) and (2) are very quick, but step (3) is very slow.

\subsection{Glass fiber transformation}

\subsubsection{XRD, SEM and EDX analysis of solid products}

Fig. 5 shows that the peak Cu intensity in the SCWO1, SCWO2 systems was weakened and that $\mathrm{CuO}$ was detected, indicating

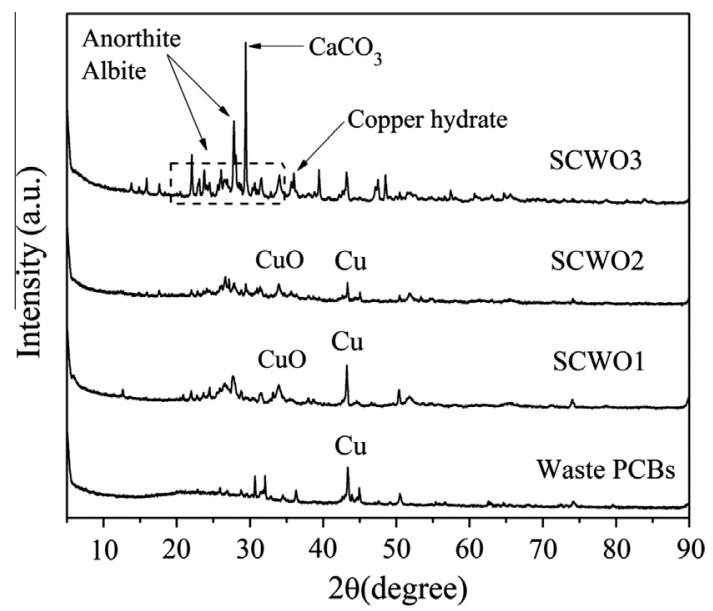

Fig. 5. XRD analysis of solid products. some $\mathrm{Cu}$ was oxidized during the SCWO treatment. In contrast, XRD of the SCWO3 system showed the generation of $\mathrm{CaCO}_{3}$ from calcium and copper hydrate from copper (Chien et al., 2000). Additionally, $\mathrm{SiO}_{2}$ was not completely converted in the SCWO1 and SCWO2 systems. However, $\mathrm{SiO}_{2}$ in $\mathrm{SCWO} 3$ systems can combine with base metals such as $\mathrm{Ca}, \mathrm{Na}$, and $\mathrm{Al}$ to generate the albite $\left[\mathrm{Na}\left(\mathrm{AlSi}_{3}\right) \mathrm{O}_{8}, \mathrm{NaCaAl}(\mathrm{Si}, \mathrm{Al})_{3} \mathrm{O}_{8}\right]$ and anorthite $\left[\left(\mathrm{CaAl}_{2} \mathrm{Si}_{2} \mathrm{O}_{8}\right),(\mathrm{Ca}\right.$, $\mathrm{Na})(\mathrm{Si}, \mathrm{Al})_{4} \mathrm{O}_{8}$ and $\left.(\mathrm{Ca}, \mathrm{Na})\left(\mathrm{Al}, \mathrm{Si}_{2}\right)_{2} \mathrm{Si}_{2} \mathrm{O}_{8}\right]$ in the presence of $\mathrm{NaOH}$. These XRD results reveal that the addition of $\mathrm{NaOH}$ can induce the transformation of glass fiber in SCWO3 system.

The microstructure and element content of the solid products at various stages (raw waste PCBs and SCWO residue) were investigated by SEM-EDX analysis. Fig. S5a shows after mechanical crushing, raw waste PCBs is cylindrical glass fiber with variable lengths, where metal components and organic compounds disperse. Fig. S5b shows that after treatment in SCWO1 system, glass fibers were in a state of erosion but still kept their original shapes, which indicated that the SCWO1 system's erosion on glass fibers was limited. Fig. S5c shows that after the treatment of SCWO2 system, the shape of glass fibers have changed significantly. Fig. S5d shows glass fibers from raw waste PCBs change into uniform solid powder after SCWO3 system treatment. It indicates that the transformation degree of glass fiber in SCWO3 system is more thoroughly than that in SCWO1 system and SCWO2 system.

Table S1 shows the information about solid residue before and after SCWO treatment, including EDX analysis (pink trims are detection range), SCWO residue productivity and chemical oxygen demand (COD). In order to estimate the decomposition efficiency of BERs, we use the variation of element $C$ to calculate the COD disposed by BERs in different SCWO systems. However, when SCWO disposes waste PCBs, not only oxygen is consumed but also atom $\mathrm{O}$ in solvent water is involved in the reaction. Meanwhile, parts of $\mathrm{C}$ product phases are $\mathrm{C}_{n} \mathrm{H}_{2 n+2}$, which are not fully $\mathrm{CO}_{2}$ and $\mathrm{H}_{2} \mathrm{O}$. Therefore, the presented figure of COD is estimated value. As seen from Fig. 6, due to the great molecular weight of BERs $\left(\mathrm{C}_{36} \mathrm{H}_{32} \mathrm{O}_{6} \mathrm{Br}_{8}: 1200 \mathrm{~g} / \mathrm{mol}\right)$, so the COD of SCWO degrading the BERs are much larger. The COD of SCWO3 disposing the BERs are $54.17 \mathrm{~g} / \mathrm{L}$.

\subsubsection{Transformation mechanisms of glass fiber}

In the proposed SCWO3 system, glass fiber can be transformed by reacting with $\mathrm{NaOH}$ through the alkali-silica reaction (ASR). The possible transformation mechanism of the $\mathrm{SiO}_{2}$ from glass fiber in SCWO3 system is as follows (Garcia-Diaz et al., 2006):

$2 \mathrm{SiO}_{2}+\mathrm{OH}^{-} \rightarrow \mathrm{SiO}_{5 / 2}^{-}+\mathrm{SiO}_{5 / 2} \mathrm{H}$

$\mathrm{SiO}_{5 / 2} \mathrm{H}+\mathrm{OH}^{-} \leftrightarrow \mathrm{SiO}_{5 / 2}^{-}+\mathrm{H}_{2} \mathrm{O}$

$\mathrm{SiO}_{5 / 2}^{-}+\mathrm{Na}^{+}+\mathrm{Ca}^{2+}+\mathrm{Al}^{3+} \rightarrow \mathrm{Na}-\mathrm{Ca}-\mathrm{Al}-\mathrm{Si}-\mathrm{O}$ compounds

where $\mathrm{Na}-\mathrm{Ca}-\mathrm{Al}-\mathrm{Si}-\mathrm{O}$ compounds represent albite and anorthite.

"Silanol" sites are negatively charged in the SCWO3 system due to attack of the hydroxide ions on the siloxane bonds in $\mathrm{SiO}_{2}$ (Eq. (1)). These silanol sites are neutralized following the equilibrium reaction in Eq. (2). In contact with $\mathrm{NaOH}$, the major Si species present is $\mathrm{SiO}_{5 / 2}^{-}$. The negatively charged silanol sites are counterbalanced by $\mathrm{Na}^{+}, \mathrm{Ca}^{2+}$ and $\mathrm{Al}^{3+}$ cations. Afterwards, precipitation of the silica ions by the cations $\left(\mathrm{Na}^{+}, \mathrm{Ca}^{2+}\right.$, and $\left.\mathrm{Al}^{3+}\right)$ will form albite and anorthite (Eq. (3)) (Gao et al., 2013).

Elliott et al. (1983) reported chemical reagents that can produce $\mathrm{OH}^{-}$in SCWO systems, will act as a catalyst and induce a water gas shift (WGS) reaction. In the SCWO3 system, the WGS reaction drives the chemical equilibrium in the forward direction. The Gibbs free energy of the WGS reaction is $-41.5 \mathrm{~kJ} / \mathrm{mol}$, indicating that the reaction is exothermic. Therefore, the WGS reaction in SCWO3 


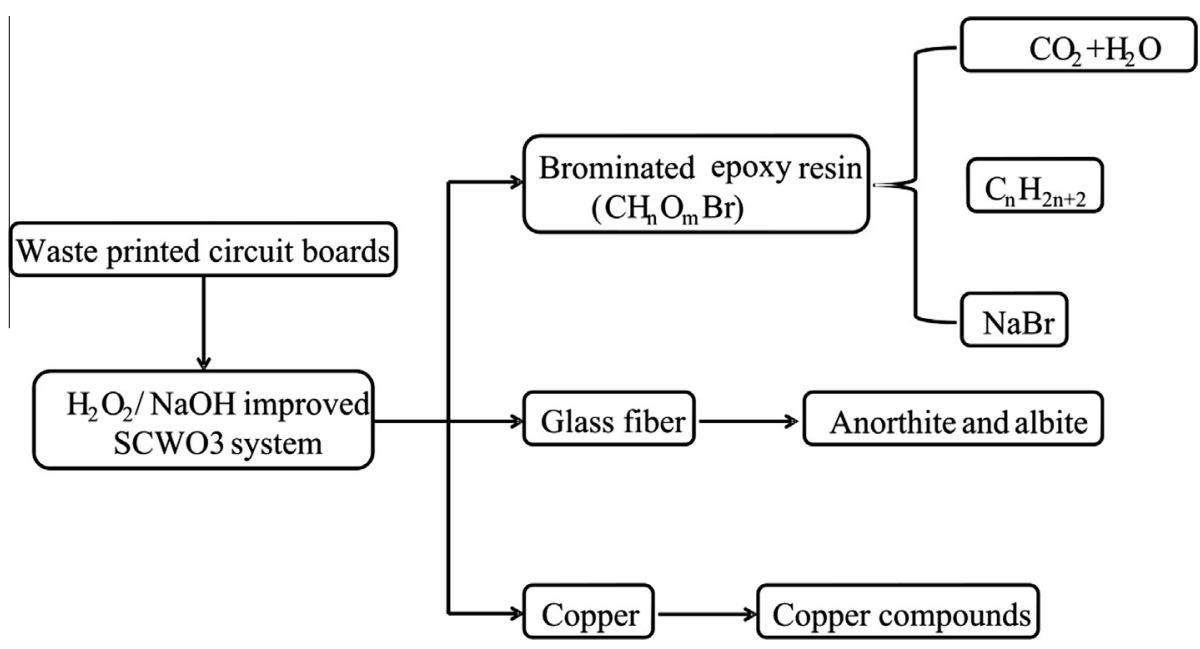

Fig. 6. $\mathrm{H}_{2} \mathrm{O}_{2} / \mathrm{NaOH}$ improved $\mathrm{SCWO} 3$ system for waste PCBs disposal.

system is spontaneous (Elliott et al., 1993). $\mathrm{NaOH}$ induces the phase transition of the calcium species in glass fiber. The possible transformation mechanism of the $\mathrm{CaO}$ in glass fiber is as follows according to the following equations (Jarana et al., 2008):

$$
\begin{aligned}
& \mathrm{CH}_{\mathrm{n}} \mathrm{O}_{\mathrm{m}} \mathrm{Br}+(1-\mathrm{m}) \mathrm{H}_{2} \mathrm{O} \rightarrow \mathrm{CO}+\mathrm{HBr}+(\mathrm{n}-2 \mathrm{~m}+1) / 2 \mathrm{H}_{2} \uparrow \\
& \mathrm{CO}+\mathrm{H}_{2} \mathrm{O} \leftrightarrow \mathrm{HCOOH} \leftrightarrow \mathrm{CO}_{2}+\mathrm{H}_{2} \uparrow \\
& \mathrm{NaOH}+\mathrm{CO} \leftrightarrow \mathrm{HCOONa} \\
& \mathrm{NaOH}+\mathrm{HCOOH} \leftrightarrow \mathrm{HCOONa}+\mathrm{H}_{2} \mathrm{O} \\
& \mathrm{HCOONa}+\mathrm{NaOH} \leftrightarrow \mathrm{Na}_{2} \mathrm{CO}_{3}+\mathrm{H}_{2} \uparrow \\
& \mathrm{CaO} \text { (glass fiber })+\mathrm{H}_{2} \mathrm{O} \rightarrow \mathrm{Ca}(\mathrm{OH})_{2} \\
& \mathrm{Na}_{2} \mathrm{CO}_{3}+\mathrm{Ca}(\mathrm{OH})_{2} \rightarrow \mathrm{CaCO}_{3} \downarrow+2 \mathrm{NaOH}
\end{aligned}
$$

$\mathrm{CO}$ and $\mathrm{CO}_{2}$ (the degradation products of BERs) were immobilized in the SCWO3 residue. The catalytic cycle is completed by the formation of $\mathrm{CaCO}_{3}$. In conclusion, $\mathrm{NaOH}$ can change the reaction pathway and accelerate the WGS reaction, reducing the overall activation energy of the reaction (Guo et al., 2010).

\subsection{Proposed SCWO3 system for the recycling of waste PCBS}

Based on the obtained results and identified products, the entire proposed SCWO3 system can be integrated and proposed in Fig. 6. After treating in SCWO3 system, the bromine from the BERs was released as $\mathrm{HBr}$ and then neutralize by $\mathrm{NaOH}$ to form $\mathrm{NaBr}$, which can reduce the equipment corrosion during the treatment process. The degradation products of BERs are hydrocarbons, which could be purified by a follow-up process and supplied as fuel for transportation. Meanwhile, $\mathrm{SiO}_{2}$ from fiberglass can combine with base metals to generate the albite and anorthite. These materials have potential application on the thermal insulation and acid resistant property. Metal species (e.g. $\mathrm{CaCO}_{3}$, copper hydrate, etc.) in SCWO residue could be recovered by a subsequent separation process (Xiu and Zhang, 2009, 2012). Hence, every part of the component in waste PCBs can be substantially recycled.

In our previous research, we once took the method of unimproved batch supercritical water to dispose waste PCBs and completed the recycling and harmless treatment of waste PCBs. Compared with traditional pyrometallurgy and hydrometallurgy, the SCWO process is greener, cleaner and more environmental friendly. Compared with the unimproved SCWO system in the terms of disposing waste PCBs and harmless treatment, the improved SCWO system has many advantages. But the improved SCWO system requires advanced crushing and screening of waste PCBs before treatment, thus the treatment cost was increased. Therefore, how to utilize the improved SCWO system to finish the batched production of completing the degradation of highmolecular organic compounds, materials transformation and metal recovery in waste PCBs and how to reduce the reaction time as well as how to lower the treating cost are going to be researched in the following studies. This study only indicates a possibility for functionalization of waste PCBs by improved SCWO system.

\section{Conclusions}

This study demonstrated that $\mathrm{H}_{2} \mathrm{O}_{2} / \mathrm{NaOH}$ improved SCWO3 system was the most suitable and efficient system for detoxification and resource transformation from waste PCBs. $\mathrm{NaOH}$ enhanced the removal efficiency of bromine through the nucleophilic substitution and elimination reaction in BERs. The optimal operational conditions for debromination were: $\mathrm{NaOH} 0.21 \mathrm{~g}, \mathrm{H}_{2} \mathrm{O}_{2}$ $9.04 \mathrm{~mL}$, reaction time $39.7 \mathrm{~min}$, respectively. Maximum debromination efficiency reached $95.14 \%$.

Waste $\mathrm{PCBs}$ in $\mathrm{H}_{2} \mathrm{O}_{2} / \mathrm{NaOH}$ improved SCWO system could be fully degraded into useful products and simultaneously transformed into functional materials. BERs completely degrades into harmless long-chain hydrocarbons, $\mathrm{CO}_{2}$ and $\mathrm{H}_{2} \mathrm{O}$ by the oxidation and ring cleavage effects of SCWO and $\mathrm{H}_{2} \mathrm{O}_{2} . \mathrm{SiO}_{2}$ in the fiberglass can be successfully converted into useful materials which can be potentially used in the fields, such as heat preservation, insulation and resistance to acid corrosion. This study showed that the SCWO system improved by exogenous additives could effectively control the degradation path and degradation products for different components of the waste PCBs.

\section{Acknowledgments}

This research was financially supported by the National Natural Science Foundation of China (51278485, 21477151), the Strategic Priority Research Program of the Chinese Academy of Sciences (XDB05050200), the National Water Pollution Control and Management Program (2012ZX07202-005) and the Science Promotion Program of Research Center for Eco-Environmental Sciences, CAS (YSW2013B05). 


\section{Appendix A. Supplementary material}

Supplementary data associated with this article can be found, in the online version, at http://dx.doi.org/10.1016/j.wasman.2016.05. 022.

\section{References}

Akcil, A., Erust, C., Gahan, C.S., Ozgun, M., Sahin, M., Tuncuk, A., 2015. Precious metal recovery from waste printed circuit boards using cyanide and non-cyanide lixiviants - a review. Waste Manage. 45, 258-271.

Bröll, D., Kaul, C., Krämer, A., Krammer, P., Richter, T., Jung, M., Vogel, H., Zehner, P., 1999. Chemistry in supercritical water. Angew. Chem. Int. Ed. 38, 2998-3014.

Chien, Y.-C., Wang, H.P., Lin, K.-S., Yang, Y.-W., 2000. Oxidation of printed circuit board wastes in supercritical water. Water Res. 34, 4279-4283.

Ding, Z.-Y., Aki, S.N., Abraham, M.A., 1995. Catalytic supercritical water oxidation: phenol conversion and product selectivity. Environ. Sci. Technol. 29, 27482753.

Dong, X., Gan, Z., Lu, X., Jin, W., Yu, Y., Zhang, M., 2015. Study on catalytic and noncatalytic supercritical water oxidation of p-nitrophenol wastewater. Chem. Eng. J. 277, 30-39.

Duan, H., Li, J., Liu, Y., Yamazaki, N., Jiang, W., 2011. Characterization and inventory of $\mathrm{PCDD} / \mathrm{Fs}$ and $\mathrm{PBDD} / \mathrm{Fs}$ emissions from the incineration of waste printed circuit board. Environ. Sci. Technol. 45, 6322-6328.

Elliott, D.C., Hallen, R.T., Sealock Jr., L.J., 1983. Aqueous catalyst systems for the water-gas shift reaction. 2. Mechanism of basic catalysis. Indust. Eng. Chem. Prod. Res. Develop. 22, 431-435.

Elliott, D.C., Sealock Jr., L.J., Baker, E.G., 1993. Chemical processing in high-pressure aqueous environments. 2. Development of catalysts for gasification. Ind. Eng. Chem. Res. 32, 1542-1548.

Fogarasi, S., Imre-Lucaci, F., Egedy, A., Imre-Lucaci, Á., Ilea, P., 2015. Eco-friendly copper recovery process from waste printed circuit boards using $\mathrm{Fe}^{3+} / \mathrm{Fe}^{2+}$ redox system. Waste Manage. 40, 136-143.

Gao, X.X., Multon, S., Cyr, M., Sellier, A., 2013. Alkali-silica reaction (ASR) expansion: pessimum effect versus scale effect. Cem. Concr. Res. 44, 25-33.

Garcia-Diaz, E., Riche, J., Bulteel, D., Vernet, C., 2006. Mechanism of damage for the alkali-silica reaction. Cem. Concr. Res. 36, 395-400.

Gopalan, S., Savage, P.E., 1994. Reaction mechanism for phenol oxidation in supercritical water. J. Phys. Chem. 98, 12646-12652.

Guan, Q., Wei, C., Chai, X.-S., 2011. Pathways and kinetics of partial oxidation of phenol in supercritical water. Chem. Eng. J. 175, 201-206.

Guo, Y., Wang, S., Xu, D., Gong, Y., Ma, H., Tang, X., 2010. Review of catalytic supercritical water gasification for hydrogen production from biomass. Renew. Sustain. Energy Rev. 14, 334-343.

Hadi, P., Ning, C., Ouyang, W., Xu, M., Lin, C.S.K., McKay, G., 2015. Toward environmentally-benign utilization of nonmetallic fraction of waste printed circuit boards as modifier and precursor. Waste Manage. 35, 236-246.

Huang, K., Guo, J., Xu, Z., 2009. Recycling of waste printed circuit boards: a review of current technologies and treatment status in China. J. Hazard. Mater. 164, 399408.

Hunter, S.E., Savage, P.E., 2004. Recent advances in acid-and base-catalyzed organic synthesis in high-temperature liquid water. Chem. Eng. Sci. 59, 4903-4909.

Jarana, M.B. Garcia, Sánchez-Oneto, J., Portela, J.R., Sanz, E.N., de la Ossa, E.M., 2008. Supercritical water gasification of industrial organic wastes. J. Supercritical Fluids 46, 329-334

Li, K., Xu, Z., 2015. Application of supercritical water to decompose brominated epoxy resin and environmental friendly recovery of metals from waste memory module. Environ. Sci. Technol. 49, 1761-1767.
Li, X.-y., Cui, Y.-h., Feng, Y.-j., Xie, Z.-m., Gu, J.-D., 2005. Reaction pathways and mechanisms of the electrochemical degradation of phenol on different electrodes. Water Res. 39, 1972-1981.

Li, Jing-ying, Xu, Xiu-li, Liu, Wen-quan, 2012. Thiourea leaching gold and silver from the printed circuit boards of waste mobile phones. Waste Manage. 32, 1209 1212.

Lin, K.-S., Wang, H.P., 1999. Rate enhancement by cations in supercritical water oxidation of 2-chlorophenol. Environ. Sci. Technol. 33, 3278-3280.

Luda, M., Balabanovich, A., Camino, G., 2002. Thermal decomposition of fire retardant brominated epoxy resins. J. Anal. Appl. Pyrol. 65, 25-40.

Matsumoto, Y., Oshima, Y., 2014. Au and Cu recovery from printed boards by decomposition of epoxy resin in supercritical water. J. Supercritical Fluids 95 $462-467$.

Onwudili, J.A., Williams, P.T., 2009. Degradation of brominated flame-retarded plastics (Br-ABS and Br-HIPS) in supercritical water. J. Supercritical Fluids 49, 356-368.

Qian, L., Wang, S., Xu, D., Guo, Y., Tang, X., Wang, L., 2016. Treatment of municipal sewage sludge in supercritical water: a review. Water Res. 89, 118-131.

Quan, C., Li, A., Gao, N., 2010. Characterization of products recycling from PCB waste pyrolysis. J. Anal. Appl. Pyrol. 89, 102-106.

Savage, P.E., 1999. Organic chemical reactions in supercritical water. Chem. Rev. 99 $603-622$.

Sun, Z., Takahashi, F., Odaka, Y., Fukushi, K., Oshima, Y., Yamamoto, K., 2007. Effects of potassium alkalis and sodium alkalis on the dechlorination of o-chlorophenol in supercritical water. Chemosphere 66, 151-157.

Wang, R., Xu, Z., 2014. Recycling of non-metallic fractions from waste electrical and electronic equipment (WEEE): a review. Waste Manage. 34, 1455-1469.

Wang, Y., Zhang, F.-S., 2012. Degradation of brominated flame retardant in computer housing plastic by supercritical fluids. J. Hazard. Mater. 205, 156-163.

Wang, C., Zhu, N., Wang, Y., Zhang, F., 2011. Co-detoxification of transformer oilcontained PCBs and heavy metals in medical waste incinerator fly ash under sub-and supercritical water. Environ. Sci. Technol. 46, 1003-1009.

Wang, S., Guo, Y., Chen, C., Zhang, J., Gong, Y., Wang, Y., 2011. Supercritical water oxidation of landfill leachate. Waste Manage. 31, 2027-2035.

Wang, R., Chen, Y., Xu, Z., 2015. Recycling acetic acid from polarizing film of waste liquid crystal display panels by sub/supercritical water treatments. Environ. Sci Technol. 49, 5999-6008.

Xing, M., Zhang, F.-S., 2013. Degradation of brominated epoxy resin and metal recovery from waste printed circuit boards through batch sub/supercritical water treatments. Chem. Eng. J. 219, 131-136.

Xiu, F.R., Zhang, F.S., 2009. Recovery of copper and lead from waste printed circuit boards by supercritical water oxidation combined with electrokinetic process. J. Hazard. Mater. 165, 1002-1007.

Xiu, F.R., Zhang, F.S., 2012. Size-controlled preparation of $\mathrm{Cu}_{2} \mathrm{O}$ nanoparticles from waste printed circuit boards by supercritical water combined with electrokinetic process. J. Hazard. Mater. 233-234, 200-206.

Xiu, F.-R., Qi, Y., Zhang, F.-S., 2013. Recovery of metals from waste printed circuit boards by supercritical water pre-treatment combined with acid leaching process. Waste Manage. 33, 1251-1257.

Xiu, F.-R., Qi, Y., Zhang, F.-S., 2014. Co-treatment of waste printed circuit boards and polyvinyl chloride by subcritical water oxidation: removal of brominated flame retardants and recovery of $\mathrm{Cu}$ and $\mathrm{Pb}$. Chem. Eng. J. 237, 242-249.

Xiu, F.-R., Qi, Y., Zhang, F.-S., 2015. Leaching of Au, Ag, and Pd from waste printed circuit boards of mobile phone by iodide lixiviant after supercritical water pretreatment. Waste Manage. 41, 134-141.

Yang, H., Liu, J., Yang, J., 2011. Leaching copper from shredded particles of waste printed circuit boards. J. Hazard. Mater. 187, 393-400.

Yin, J., Li, G., He, W., Huang, J., Xu, M., 2011. Hydrothermal decomposition of brominated epoxy resin in waste printed circuit boards. J. Anal. Appl. Pyrol. 92, $131-136$.

Zhang, K., Schnoor, J.L., Zeng, E.Y., 2012. E-waste recycling: where does it go from here? Environ. Sci. Technol. 46, 10861-10867. 